\section{DESIGN OF ALGORITHMS FOR AUTOMATIC SELECTION OF DRIVE UNITS FOR
MECHATRONIC DEVICES}

ZDENEK ZEMAN, MILAN MIHOLA, JIRI SUDER

VSB - Technical University of Ostrava, Department of Robotics, Ostrava, Czech Republic

DOI : 10.17973/MMSJ.2021_6_2021011 e-mail: zdenek.zeman@vsb.cz

The design and selection of a suitable drive unit for use in mechatronic systems is a process that can be demanding not only in terms of the time required but also in terms of the demands placed on the knowledge and experience of development workers. The development aimed to create algorithms for the selection of compact electric power units based on data from dynamic analyses of the proposed system, with the help of which it would be possible to shorten and simplify the drive unit selection process significantly. The result of the development is a software tool called DrivePicker. Its functions and benefits are demonstrated in the design of drive units for a robotic arm with an angular structure and 5 degrees of freedom. Comparing selected units from two manufacturers (Spinea DS and HarmonicDrive CanisDrive) shows that by using this software tool, we can significantly speed up and streamline the design of mechatronic devices. DrivePicker also has an interface for connection to simulation and CAD systems, which opens up the possibility of further autonomy.

KEYWORDS

Drive, Design, Automatization, Mechatronic

\section{INTRODUCTION}

Today, when designing new equipment, great emphasis is placed on minimizing the cost of the design itself and the time it takes. Within these requirements, various software tools are being introduced, the task of which is to speed up and simplify particular parts of the design process of new devices. These software tools reduce the design time, but also, thanks to their partial or complete automation, they reduce the requirements on design workers' knowledge.

There are currently several software tools on the market for the design of standardized machine parts, such as bolts, bearings, gears, etc., either in the form of stand-alone applications (e.g. MitCalc [MITCalc 2021]) or as part of one of the CAD systems (e.g. KISSsoft [KISSsoft 2021]). The calculations based on which machine parts are designed and inspected with the help of these software tools are, in most cases, based on generally known standards and procedures relating to the given types of machine parts (ANSI, DIN, ISO, etc.). As part of further research, these software tools are connected to CAD systems to create autonomous units, where the individual software automatically transfers inputs and outputs to each other. With this connection, we can achieve automation of the design of structural units or parts of equipment. Reddy and Sridhar presented a tool for parametric modeling of bolts, nuts and bearings [Reddy 2015] Reddy and Venkatachalapathi have created a tool for flexible modeling of industrial battery box assemblies using a knowledge base [Reddy 2018]. In both cases, the tools use the SolidWorks Software Application Interface (API).
The situation is already different for the design of non-standard parts such as drive units. Some manufacturers provide online software tools for the selection of suitable drive units, but their applicability is very limited and only applies to the manufacturer's products. The rest of the manufacturers only provide the given procedure for the drive unit selection in the catalogue format. The actual calculation and selection of the drive unit is then left to the development worker.

By creating software tools that work with an assortment of several manufacturers, it is possible to significantly speed up the design and selection of these non-standard elements, including comparing similar elements from different manufacturers and selecting an element that complies with the design conditions same as it is with standard parts.

\section{DRIVE PICKER}

Drive Picker is a software tool developed to select compact power units for various single-purpose mechatronic devices based on data from dynamic motion analyses that can be performed using multiple CAD systems. The primary purpose of this software is to speed up and streamline a given part of the design process of mechatronic devices and, at the same time, reduce the demands on the knowledge and experience of development workers. With the use of the DrivePicker software tool, it is very easy to perform optimization iterations. Choosing a new drive unit will take the development worker only a fraction of the time it takes to manually design a new drive unit using recommended procedures from the manufacturer's catalogue.

\subsection{Drive Picker software tool GUI}

The user works with the software tool via its graphical user interface (GUI), consisting of three main panels (see Fig. 1). The panel with the New Project button located at the top of the application window is used to start a new project. After pressing this button, a dialogue box is displayed, with which the user defines all input data needed for selecting the drive unit. The user can enter data to select up to six drive units at once in one project. The second panel, located on the left side of the window, is the control panel. In addition to the control buttons, this panel also contains a list of data sets filled by the user for selecting individual drive units. If input data is entered for selecting multiple drive units, the user can switch between which units the data are currently displayed in the third display panel. The display panel is then used to display the inputs and outputs of the application to the user.

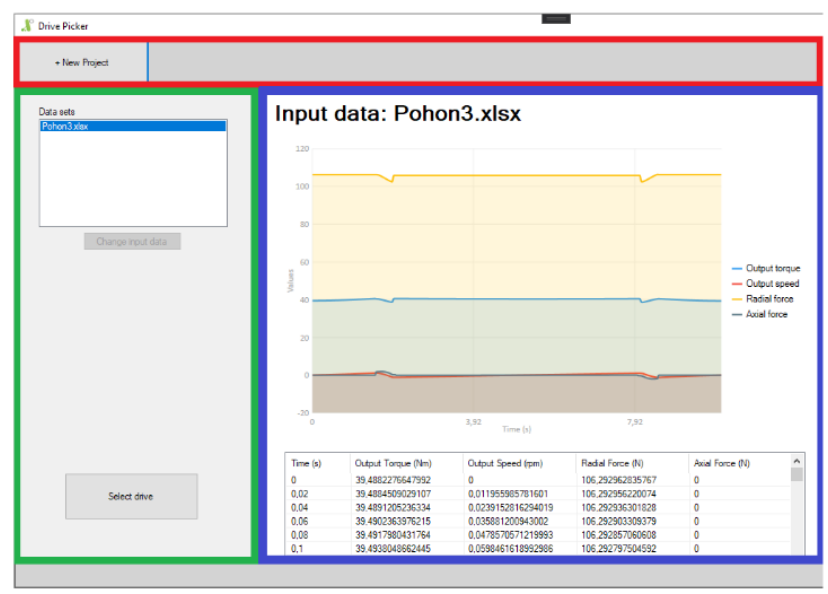

Figure 1. The graphical user interface of the application (Red - New Project panel, Green - Control panel, Blue - Display panel) 
In Fig.2, you can see the dialogue window for entering input data. The drive units are selected based on the course of the required output torque, output speed and the axial and radial forces acting on the output flange of the drive unit for a given time. These data can be obtained, for example, by exporting their course from analyzes performed in CAD software. The data is entered into the application via a properly formatted file, in which the input data is stored in a column format in a precisely defined order (time, output torque, output speed, radial force, axial force). Supported input file formats are .txt .$x m l$ and .csv. The Drive Picker software tool then converts this data into a graph, allowing for easier visual inspection. Other input values for selecting the drive unit are the moment of inertia of the load, the minimum required service life of the drive unit bearings and the lengths Lr and La, representing the distances from the drive units flange in which axial and radial forces act from the load. These values are entered manually by the user via the GUI of an application together with other optional custom requirements for the final selected drive unit, such as the maximum length, the manufacturer and the drive unit type.

\begin{tabular}{|c|c|c|}
\hline New project & & \\
\hline \multicolumn{3}{|l|}{ Select file } \\
\hline Pohon 3xlsx & $\checkmark$ & Add files \\
\hline \multicolumn{3}{|l|}{ Input values } \\
\hline Load inertia & 1 & kgm2 \\
\hline Minimum bearing life & 10000 & $\mathrm{~h}$ \\
\hline Lenght $\mathrm{Lr}$ & 0,25 & $\mathrm{~m}$ \\
\hline Lenght La & 0,03 & $\mathrm{~m}$ \\
\hline$\square$ Action tipping torque & 0 & $\mathrm{Nm}$ \\
\hline \multicolumn{3}{|l|}{ User defined input } \\
\hline Max. drive lenght & 250 & $\mathrm{~mm}$ \\
\hline Max. voltage & & $v$ \\
\hline Max. size & & $\mathrm{mm}$ \\
\hline \multirow[t]{3}{*}{$\square$ Pick one drive only } & \multicolumn{2}{|c|}{$\square$ Pick only from SpineaDS } \\
\hline & \multicolumn{2}{|c|}{$\square$ Pick only from Canis Drive } \\
\hline & & Cancel \\
\hline
\end{tabular}

Figure 2. The dialogue box for entering input data

After entering all the necessary data, it is possible to proceed to the design of a suitable drive unit. The software tool gradually reads algorithms and data from the knowledge database, with the help of which the most suitable drive units are searched according to the specified loads and other criteria from every type and series of each manufacturer, whose parameters meet the requirements. The result is a list containing the most suitable drive unit from each series of the given manufacturers (Fig. 3). If the user has checked the "Select only one most suitable unit" option when entering the input data, then the size and weight of the selected drive units from the list are further compared. The result is then one most suitable drive unit that meets the specified parameters.

\begin{tabular}{|lll|l|l|}
\hline HD CanisDrive & size: 17A & $\mathrm{i}=100$ & Drive Info & Calculations \\
\hline Spinea DS & size: DS095 & $\mathrm{i}=73$ & Drive Info & Calculations \\
\hline
\end{tabular}

Figure 3. List of suitable selected power units

\subsection{Selection algorithms}

The procedure for designing a drive unit for most drives can be summarized in the following points: performing a load analysis with subsequent determination of the load torque and the moment of inertia of the masses. Then follows a preliminary design of the type size of the motor by comparing the determined combination of load torque at a given speed with the maximum values of torque and speed of the motor. When the moment of inertia of the preselected motor is taken into account, the actually required motor torque in the operating cycle, including transient states, is then determined. The last step is to do the check calculations of the pre-designed motor. The maximum and average load torque at a given speed is compared to the maximum and nominal torque and motor speed. Most of the kinematic arrangements of the drive with an electrtic engine contain a transmission. For the preliminary motor design, it is advisable to convert the load moments to one place, either to the motor shaft or, in the case of compact drive units, to the gearbox shaft.

In the case of the design of compact drive units for use in singlepurpose mechatronic devices, in addition to checking the torques and speeds, it is also necessary to perform bearing checks using force analyzes. In addition to the static and dynamic load capacity and bearing life check, the tilting moment acting on the gearbox shaft and the subsequent tilting angle, which can be reflected in the positioning accuracy of the resulting mechatronic device, are also calculated. These calculations vary according to the type and design of the gearbox, and each manufacturer, therefore, states his calculations.

The DrivePicker software tool in its current form contains algorithms for selecting compact power units from manufacturers HarmonicDrive [Harmon Drive 2021] and Spinea [Spinea 2021], more specifically, the HarmonicDrive CanisDrive and Spinea DS series. These are drive units with a harmonic and cycloidal gearbox. In these types of drive units, most of the force effects are exerted on the bearing in the drive unit's output flange; therefore, this bearing's inspection plays a vital role in their design. When designing drive units, we work with a large amount of technical data and other data such as graphs of torque curves. The basis of the software tool is, therefore, a database in which everything needed is stored. At present, the knowledge base is built on the MySQL platform for online use and in the form of text files inside the application for offline use. 


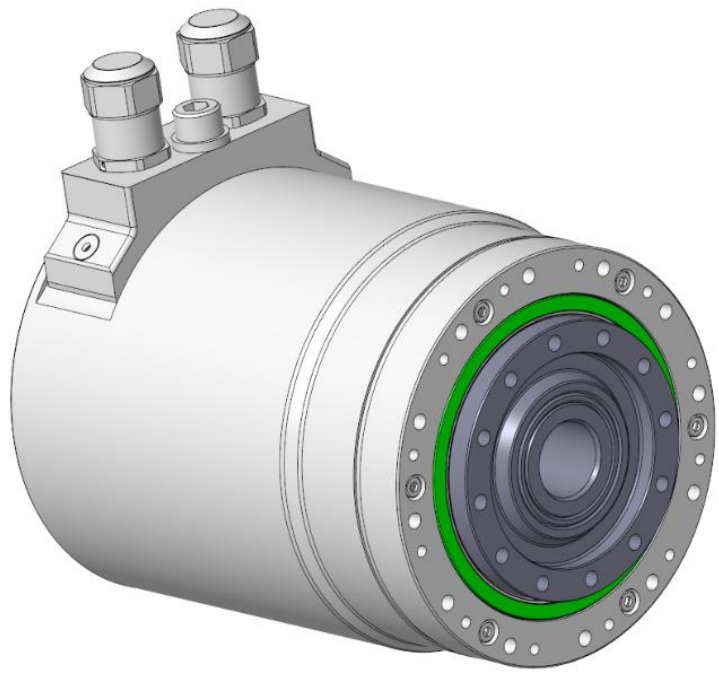

Figure 4. 3D model of Harmonic Drive Canis Drive, Green - bearing position in the output flange

The design of compact electric drive units is performed according to the instructions of their manufacturers. These instructions are prepared in various forms. Fig. 5 shows the procedure for the design of the DS series Spinea drive unit. The drive unit is designed from the point of view of the course of the load by the output torque, the moment of inertia and the course of the output speed. The unit designed in this way must then be inspected from the point of view of the force load of the output flange by radial and axial force and tilting moment, resp-their courses.

The algorithm first reads the load input values and drive unit data from the database. Then the individual partial inspections are calculated. First, the average values of load torque and speed are compared to the nominal values of the drive unit. Then the bearing service life is calculated, and after that the maximal speed is checked. Furthermore braking torque is calculated and compared to maximal torque of the drive unit The emergency torque is calculated, which determines safety, and after that the algorythm proceeds to calculate the dynamic and static bearing capacity, tilt torque and angle and check the maximum load forces on the drives shaft.

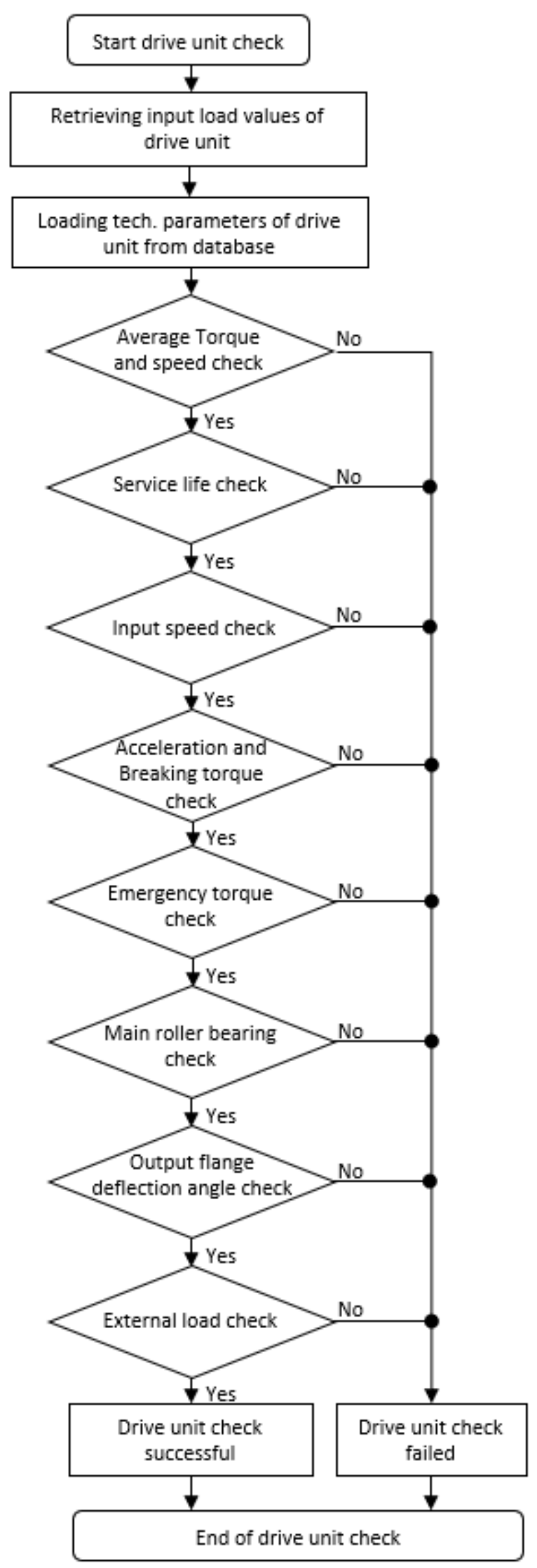

Figure 5. Algorithm for the design of the drive unit Spinea DS 
To automate the design process of drive units selection, it is necessary to create algorithms that include not only all of the necessary design calculations but also logic to quickly find a suitable unit from the list of units and logic for filtering noncompliant units according to user-specified boundary conditions. Fig. 6 shows an example of an algorithm designed to quickly find a suitable drive unit from a given type series. The block diagram from Fig. 5 can be substituted for the drive unit control block.

As can be seen, before it is possible to proceed to the actual selection of the drive unit, the algorithm must first process the input data, where the maximum, minimum and average values of output torque, speed and radial and axial forces are calculated from the given load data.

In the next step, the algorithm reads the drive units technical data from the database and inserts it into the list. This list contains all power units from the given series, sorted from the smallest in performance to the largest. When designing drive units for single-purpose mechatronic devices, drive units of the smallest possible weight and size are sought, which meet the given requirements. Therefore, the units in the list are also arranged from the smallest in size and weight (the smallest unit in terms of performance is also the smallest in size and weight). If two power units have the same size and weight, but due to different gear ratios can one unit achieve a higher maximum torque and the other a higher maximum speed, they are both in terms of suitability for the task identical, as long as they both fulfil the requirements of the task assigned to them.

From this list, the algorithm will search for the most suitable power unit. To make sure the algorithm does not have to control all units in the list from the smallest to the largest, which would be very inefficient if the suitable unit was located at the end of it, the list's length is reduced using the half interval method. The algorithm always takes the total number of units in the list and checks the unit located precisely in its middle. If the drive unit check is successful, units in the bottom half of the list are thrown away. Otherwise, the units from the top half of the list are thrown away. This is repeated until the list contains less than five units. Then, among these remaining units, the algorithm finds the most suitable unit by checking one by one until it finds the smallest one that matches the entered input values. This unit is then added to the final list of suitable drive units from each manufacturers series, and the whole procedure is repeated for another series from another manufacturer.

After the selection of drive units is completed, it is checked whether the selected units are really the smallest and lightest in their series. This is accomplished by checking the one size smaller drive units in the series. After confirming that the selected drive unit is the smallest unit meeting the specified conditions, the user has the option of selecting a drive unit of a different gear ratio by selecting which other parameters in addition to size and weight have priority over the others. The user selects the sequence of the importance of other main parameters of the drive unit, such as max. Torque, speed, service life, etc. and with the help of value analysis, the algorithm offers him the corresponding unit.

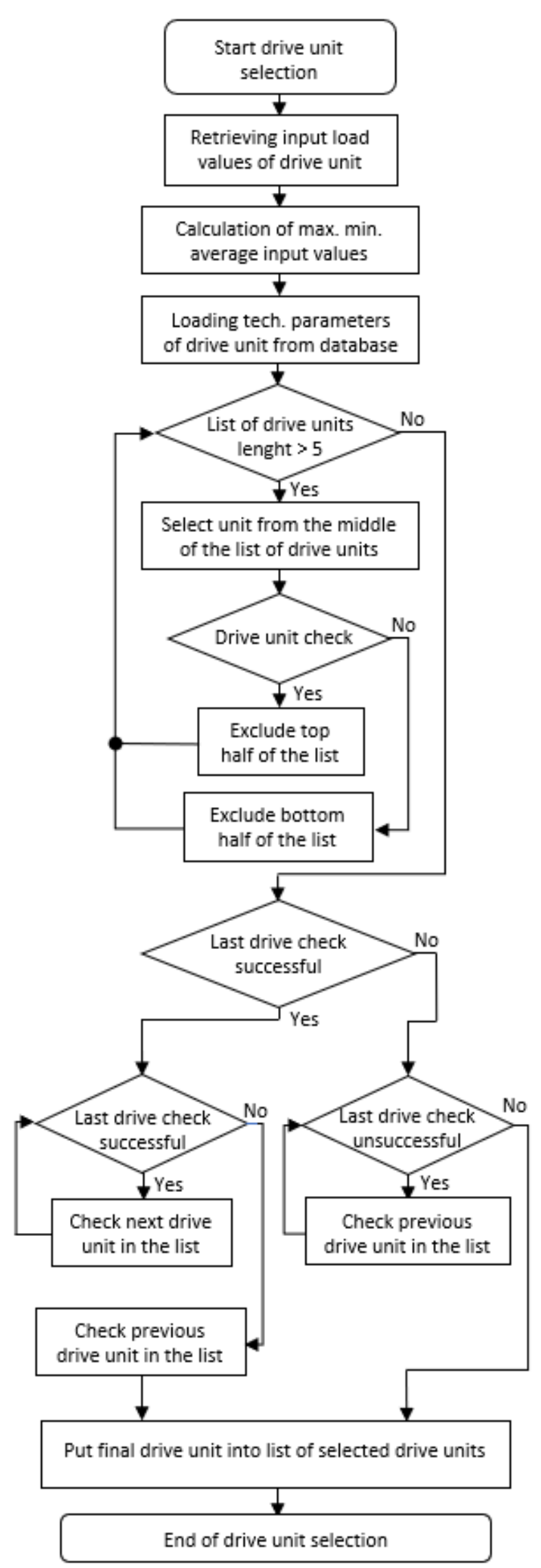

Figure 6. Algorithm for selecting the drive unit of the given manufacturer 
The resulting list of suitable drive units, in which there is always one suitable drive unit from each of the manufacturers, is further passed through an output filter, where their size and weight are compared. The algorithm's outputs are the technical parameters and the results of individual steps of the selected drive unit's design calculations, which the user can view through the GUI of the application. The user can check the calculation results, or if no unit was found, find out why. However, this already considers that the user is familiar with the design calculations of drive units and can find out, based on the results, where in the input data it is necessary to make a change. The technical documentation of the manufacturers, according to which the computational algorithms are designed, can be helpful in this case.

\subsection{Possibilities of connection between DrivePicker software tool with other software}

As part of further development, the DrivePicker software tool connects directly to SolidWorks CAD software through its API interface, as well as with other applications whose functions precede or follow the design of drive units. The complete vision is a fully automated design of robotic arms by cooperation with SolidWorks and additional applications such as DrivePicker. Software tools will directly pass their inputs and outputs to each other. They will autonomously design the entire system according to user-specified boundary conditions, including its optimization using the iteration process. The designed system parameters are used as input for the next iteration, and it is checked whether it is not possible further to optimize the whole system in any design step. Fig. 7 shows a block diagram of a potential system proposed for this task.

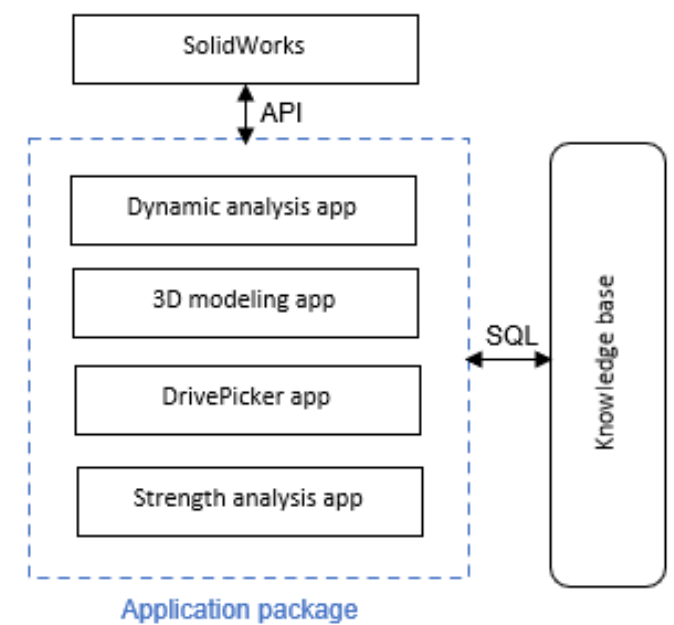

Figure 7. Block diagram of a possible application package for automated design of robot arms

An example of a connectable software application to achieve this goal is the mentioned software tool for 3D modeling and assembly of industrial battery boxes developed as part of the Development of a knowledge system for creating CAD models ( $E$. Jayakiran Reddy) [Reddy 2018]. The software tool generates different models with the help of parts of the code stored in the knowledge database. It is possible to change the dimensions of these models using variables inside the parts of the code or form different connection interfaces to the same component by changing the parts of the code. If the given knowledge database were supplemented with parts of the codes for, e.g. the creation of flanges, it would be possible to connect different parts of the code to generate flanges for the given unit selected by DrivePicker with a compatible connection interface, or even to create complete sets of devices on which dynamic analyzes could be performed. From these analyses, data could be collected for further iterations of drive units' choices using the DrivePicker software. To do this, it would only be necessary to ensure that the given applications send their inputs and outputs to each other, e.g. via communication using the ICP / IP protocol, or in case the applications are developed in the same programming language, merged into one unit. In this sense, DrivePicker software is developed to be very easily connected to other software as a stand-alone unit, which can be called through the code as a single method.

\section{EXPERIMENT}

The Drive Picker software tool's functionality was verified on a demonstration task of designing drive units for a robotic arm with an angular structure and 5 degrees of freedom. The 3D model (Fig. 8) of the arm was used to obtain torque values, speed and forces acting in individual arm joints. Within the three dynamic analyses performed, based on different trajectories of the manipulation object's movement, suitable drive units were gradually selected into each manipulator's joint using the Drive Picker software.

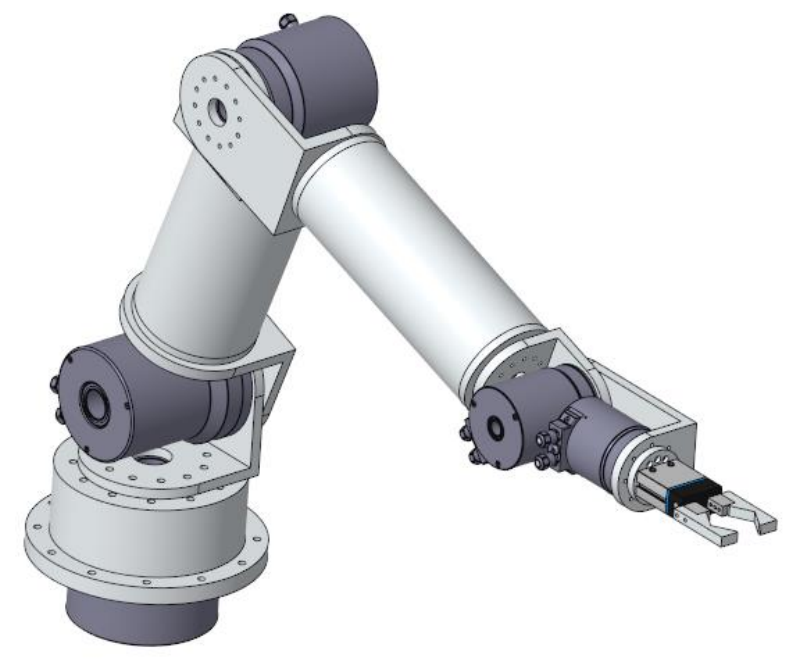

Figure 8. Kinematic model of the robot arm

In the first analysis, a manipulation object weighing $1.1 \mathrm{Kg}$ travelling along a trajectory 1 with a length of $1100 \mathrm{~mm}$ was manipulated (Fig. 9). For the second analysis, only the handling object's weight was changed to $5.5 \mathrm{Kg}$ to compare the differences between the designed drive units for the same trajectory, but the different weight of the handling object. In the third analysis, a manipulation object of the same weight of $5.5 \mathrm{Kg}$ travelling along trajectory 2 with a length of $5700 \mathrm{~mm}$ was manipulated (Fig. 10). Here, the purpose was to compare the differences between the proposed power units at the same weight of the manipulation object and different trajectories. The acceleration and velocity of the arm endpoint were the same for all analyzes. 


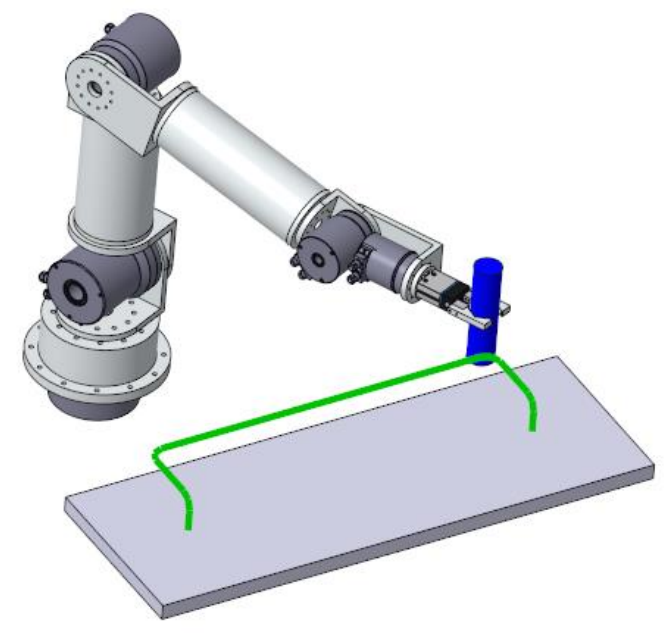

Figure 9. Trajectory 1

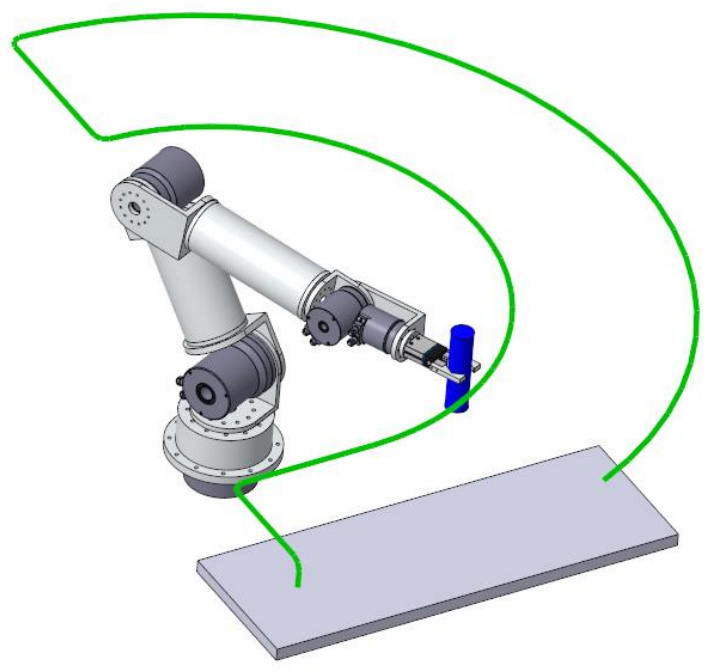

Figure 10. Trajectory 2

The individual courses of torque, speed and radial and axial force in a given joint, which act on the selected drive unit, obtained from the analyses were exported in the form of a text file, which was used as input Drive Picker software tool. The joints are numbered in order from the location closest to the end effector (Joint 1) to the robotic arm's base (Joint 5). Below you can see the graphs Fig.11, Fig.12 and Fig.13, which show the course of values for Joint 3 for all three performed analyzes.

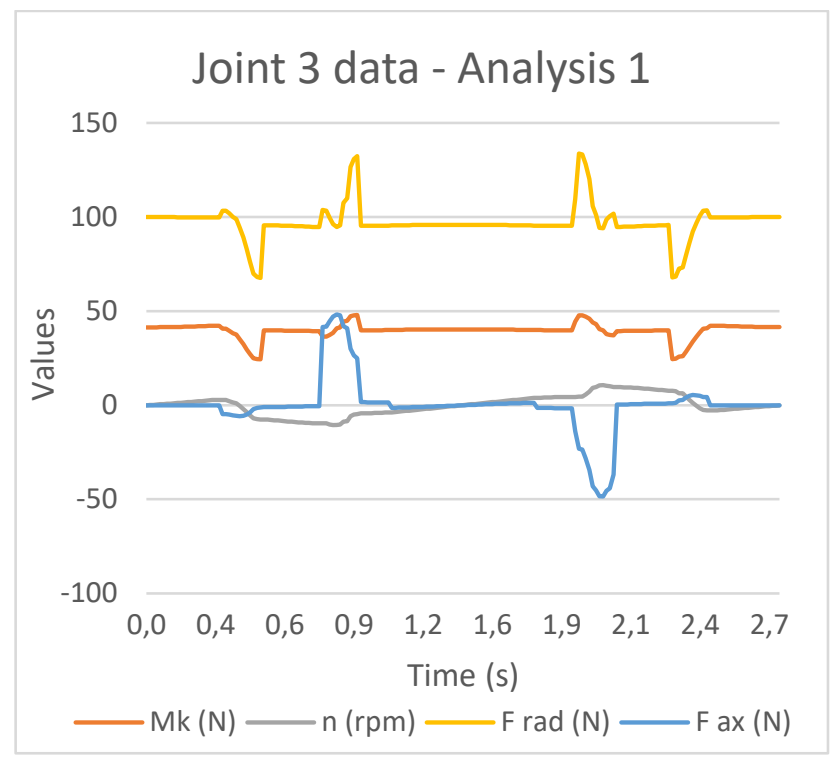

Figure 11. Graph of the course of values in arm three for the first analysis

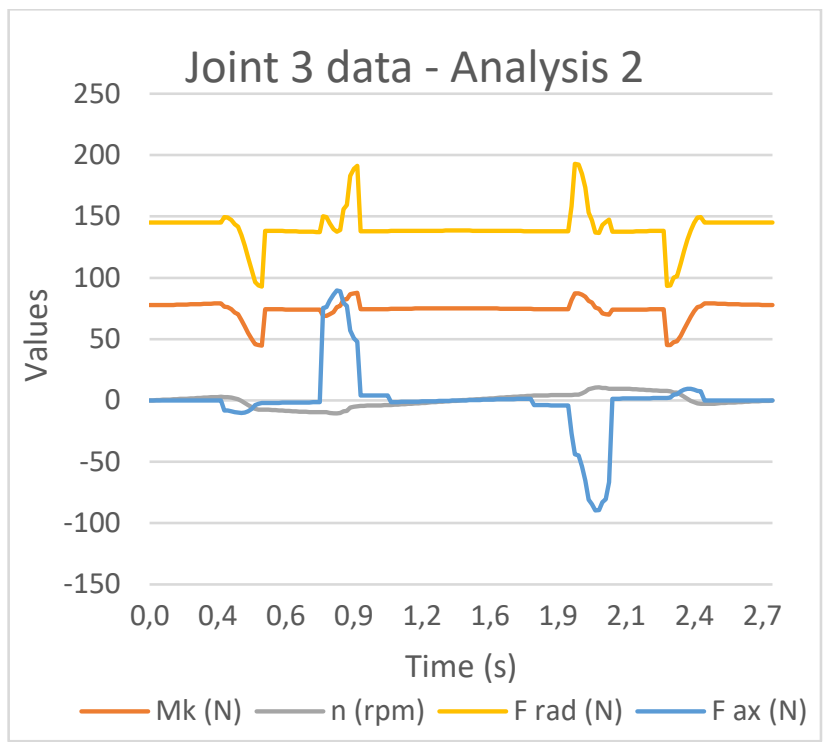

Figure 12. Graph of the course of values in arm three for the second analysis

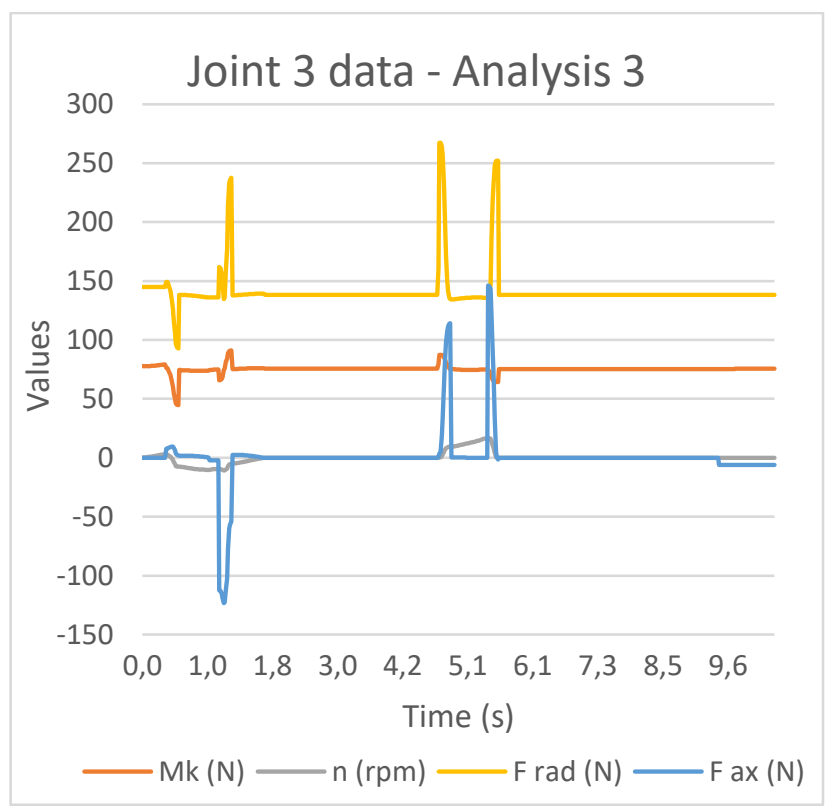

Figure 13. Graph of the course of values in arm three for the third analysis 
The drive units were always selected sequentially from Joint 1. Once the first drive unit was designed, it was necessary to place its 3D model into the joint with the correct set weight and inertia moments. Based on the newly performed dynamic analysis, the basis for the drive unit design for joint two was obtained. Table 2 lists all the designed drive units for each of the performed analyzes. It also shows the maximum, average and minimum values of torques, output speeds, radial and axial forces related to individual joints. The resulting drive unit was selected from the available Harmonic Drive Canis Drive and Spinea DS series. For comparison of manufacturers, there is also an alternative to every selection from another manufacturer. The one with the lowest weight was selected as the final unit.

\begin{tabular}{|c|c|c|c|c|}
\hline \multicolumn{5}{|c|}{ Joint 1} \\
\hline \multicolumn{2}{|c|}{ Values } & $\begin{array}{c}\text { Analysis } \\
1\end{array}$ & $\begin{array}{c}\text { Analysis } \\
2\end{array}$ & $\begin{array}{c}\text { Analysis } \\
3\end{array}$ \\
\hline \multirow{3}{*}{$\begin{array}{l}\text { Output } \\
\text { Torque } \\
\text { [ Nm ] }\end{array}$} & Max. & $2,1 \mathrm{E}-11$ & $9,8 \mathrm{E}-11$ & 2,3 E-09 \\
\hline & Avg. & $1,4 \mathrm{E}-11$ & $6,6 \mathrm{E}-11$ & $3,1 \mathrm{E}-10$ \\
\hline & Min. & 3,3 E-14 & $1,0 \mathrm{E}-13$ & $7,1 \mathrm{E}-14$ \\
\hline \multirow{3}{*}{$\begin{array}{l}\text { Output } \\
\text { Speed } \\
\text { [ rpm ] }\end{array}$} & Max. & $3,9 \mathrm{E}-13$ & 3,9 E-13 & $5,1 \mathrm{E}-12$ \\
\hline & Avg. & $1,7 \mathrm{E}-13$ & $1,7 \mathrm{E}-13$ & $1,8 \mathrm{E}-12$ \\
\hline & Min. & 0,00 & 0,00 & 0,00 \\
\hline \multirow{2}{*}{$\begin{array}{l}\text { Radial } \\
\text { force }\end{array}$} & Max. & 23,13 & 82,43 & 105,04 \\
\hline & Avg. & 17,58 & 61,5 & 60,02 \\
\hline [ N ] & Min. & 10,08 & 35,17 & 35,16 \\
\hline \multirow{3}{*}{$\begin{array}{c}\text { Axial force } \\
\text { [ N ] }\end{array}$} & Max. & 16,69 & 58,13 & 88,21 \\
\hline & Avg. & 4,73 & 16,47 & 15,73 \\
\hline & Min. & $3,1 \mathrm{E}-10$ & $1,1 \mathrm{E}-10$ & 2,3 E-04 \\
\hline \multirow{2}{*}{$\begin{array}{l}\text { Picked } \\
\text { Drive unit }\end{array}$} & Type & $\begin{array}{c}\text { Spinea } \\
\text { DS050 } \\
\text { (ratio 63) }\end{array}$ & $\begin{array}{c}\text { Spinea } \\
\text { DS050 } \\
\text { (ratio 63) }\end{array}$ & $\begin{array}{c}\text { Spinea } \\
\text { DS050 } \\
\text { (ratio 63) }\end{array}$ \\
\hline & $\begin{array}{l}\text { Mass } \\
{[\mathrm{kg}]}\end{array}$ & 1,4 & 1,4 & 1,4 \\
\hline \multirow[t]{2}{*}{$\begin{array}{c}\text { Alternative } \\
\text { Drive unit }\end{array}$} & Type & $\begin{array}{c}\text { HD CD } \\
14 \mathrm{~A} \\
\text { (ratio 50) }\end{array}$ & $\begin{array}{c}\text { HD CD } \\
14 \mathrm{~A} \\
\text { (ratio 50) }\end{array}$ & $\begin{array}{c}\text { HD CD } \\
14 \mathrm{~A} \\
\text { (ratio 50) }\end{array}$ \\
\hline & $\begin{array}{l}\text { Mass } \\
{[\mathrm{kg}]}\end{array}$ & 1,7 & 1,7 & 1,7 \\
\hline
\end{tabular}

Table 1. Results of drive selection for Joint 1

\begin{tabular}{|c|c|c|c|c|}
\hline \multicolumn{5}{|c|}{ Joint 2} \\
\hline \multicolumn{2}{|c|}{ Values } & Analysis & Analysis & $\begin{array}{c}\text { Analysis } \\
3\end{array}$ \\
\hline \multirow{3}{*}{$\begin{array}{c}\text { Output } \\
\text { Torque } \\
\text { [ Nm ] }\end{array}$} & Max. & 6,82 & 20,92 & 20,89 \\
\hline & Avg. & 6,52 & 20,01 & 19,79 \\
\hline & Min. & 3,78 & 11,6 & 11,6 \\
\hline \multirow{3}{*}{$\begin{array}{l}\text { Output } \\
\text { Speed } \\
\text { [ rpm ] }\end{array}$} & Max. & 4,04 & 4,04 & 6,09 \\
\hline & Avg. & 1,08 & 1,08 & 0,43 \\
\hline & Min. & 0,00 & 0,00 & 0,00 \\
\hline \multirow{3}{*}{$\begin{array}{c}\text { Radial } \\
\text { force } \\
{[\mathrm{N}]}\end{array}$} & Max. & 56,55 & 115,68 & 148 \\
\hline & Avg. & 41,61 & 85,15 & 88,54 \\
\hline & Min. & 24,08 & 49,28 & 49,28 \\
\hline \multirow{3}{*}{$\begin{array}{c}\text { Axial force } \\
\text { [ N ] }\end{array}$} & Max. & 32,16 & 73,53 & 113,07 \\
\hline & Avg. & 8,67 & 19,79 & 51,18 \\
\hline & Min. & 0 & 0 & 0 \\
\hline \multirow{2}{*}{$\begin{array}{c}\text { Picked } \\
\text { Drive unit }\end{array}$} & Type & $\begin{array}{c}\text { Spinea } \\
\text { DS050 } \\
\text { (ratio 63) }\end{array}$ & $\begin{array}{c}\text { HD CD } \\
17 A \\
\text { (ratio 50) }\end{array}$ & $\begin{array}{c}\text { HD CD } \\
17 A \\
\text { (ratio 50) }\end{array}$ \\
\hline & $\begin{array}{l}\text { Mass } \\
{[\mathrm{kg}]}\end{array}$ & 1,4 & 2,3 & 2,3 \\
\hline \multirow[t]{2}{*}{$\begin{array}{l}\text { Alternative } \\
\text { Drive unit }\end{array}$} & Type & $\begin{array}{c}\text { HD CD } \\
14 \mathrm{~A} \\
\text { (ratio 50) }\end{array}$ & $\begin{array}{c}\text { Spinea } \\
\text { DS070 } \\
\text { (ratio 57) }\end{array}$ & $\begin{array}{c}\text { Spinea } \\
\text { DS070 } \\
\text { (ratio 57) }\end{array}$ \\
\hline & $\begin{array}{l}\text { Mass } \\
{[\mathrm{kg}]}\end{array}$ & 1,7 & 3,4 & 3,4 \\
\hline
\end{tabular}

Table 2. Results of drive selection for Joint 2

\begin{tabular}{|c|c|c|c|c|}
\hline \multicolumn{5}{|c|}{ Joint 3} \\
\hline \multicolumn{2}{|c|}{ Values } & Analysis & Analysis & Analysis \\
\hline \multirow{3}{*}{$\begin{array}{l}\text { Output } \\
\text { Torque } \\
\text { [ Nm ] }\end{array}$} & Max. & 47,97 & 87,72 & 91,13 \\
\hline & Avg. & 39,66 & 74,04 & 74,47 \\
\hline & Min. & 24,41 & 44,68 & 44,67 \\
\hline \multirow{3}{*}{$\begin{array}{l}\text { Output } \\
\text { Speed } \\
\text { [ rpm ] }\end{array}$} & Max. & 10,7 & 10,7 & 16,5 \\
\hline & Avg. & 3,74 & 3,74 & 1,56 \\
\hline & Min. & 0,00 & 0,00 & 0,00 \\
\hline \multirow{3}{*}{$\begin{array}{c}\text { Radial } \\
\text { force } \\
\text { [ N ] }\end{array}$} & Max. & 133,74 & 192,86 & 267,35 \\
\hline & Avg. & 96,38 & 139,3 & 143,37 \\
\hline & Min. & 67,64 & 92,81 & 92,8 \\
\hline \multirow{3}{*}{$\begin{array}{c}\text { Axial force } \\
\text { [ N ] }\end{array}$} & Max. & 48,44 & 89,64 & 146,21 \\
\hline & Avg. & 24,07 & 44,64 & 56,43 \\
\hline & Min. & 0 & 0 & 0 \\
\hline \multirow{2}{*}{$\begin{array}{c}\text { Picked } \\
\text { Drive unit }\end{array}$} & Type & $\begin{array}{c}\text { HD CD } \\
17 A \\
\text { (ratio100) }\end{array}$ & $\begin{array}{c}\text { Spinea } \\
\text { DS095 } \\
\text { (ratio 95) }\end{array}$ & $\begin{array}{c}\text { Spinea } \\
\text { DS095 } \\
\text { (ratio 95) }\end{array}$ \\
\hline & $\begin{array}{l}\text { Mass } \\
{[\mathrm{kg}]}\end{array}$ & 2,3 & 5,9 & 5,9 \\
\hline \multirow{3}{*}{$\begin{array}{c}\text { Alternative } \\
\text { Drive unit }\end{array}$} & Type & $\begin{array}{l}\text { Spinea } \\
\text { DS095 }\end{array}$ & $\begin{array}{c}\text { HD CD } \\
25 A\end{array}$ & $\begin{array}{c}\text { HD CD } \\
25 A\end{array}$ \\
\hline & & & $\begin{array}{c}\text { (ratio } \\
100)\end{array}$ & $\begin{array}{l}\text { (ratio } \\
100)\end{array}$ \\
\hline & $\begin{array}{l}\text { Mass } \\
{[\mathrm{kg}]}\end{array}$ & 5,9 & 6 & 6 \\
\hline
\end{tabular}

Table 3. Results of drive selection for Joint 3 


\begin{tabular}{|c|c|c|c|c|}
\hline \multicolumn{5}{|c|}{ Joint 4} \\
\hline \multicolumn{2}{|c|}{ Values } & Analysis & $\begin{array}{c}\text { Analysis } \\
2\end{array}$ & $\begin{array}{c}\text { Analysis } \\
3\end{array}$ \\
\hline \multirow{3}{*}{$\begin{array}{l}\text { Output } \\
\text { Torque } \\
\text { [ Nm ] }\end{array}$} & Max. & 71,84 & 126,26 & 224,25 \\
\hline & Avg. & 48,99 & 88,24 & 84,14 \\
\hline & Min. & 0,6 & 1,16 & 3,07 \\
\hline \multirow{3}{*}{$\begin{array}{l}\text { Output } \\
\text { Speed } \\
\text { [ rpm ] }\end{array}$} & Max. & 10,23 & 10,23 & 15,41 \\
\hline & Avg. & 3,54 & 3,54 & 1,69 \\
\hline & Min. & 0,00 & 0,00 & 0,00 \\
\hline \multirow{2}{*}{$\begin{array}{l}\text { Radial } \\
\text { force }\end{array}$} & Max. & 217,34 & 321,17 & 468,11 \\
\hline & Avg. & 178,97 & 254,57 & 260,08 \\
\hline [ N ] & Min. & 150,26 & 207,31 & 207,31 \\
\hline \multirow{3}{*}{$\begin{array}{c}\text { Axial force } \\
\text { [ N ] }\end{array}$} & Max. & 49,26 & 91,06 & 161,77 \\
\hline & Avg. & 24,45 & 45,37 & 53,82 \\
\hline & Min. & 0 & 0 & 0 \\
\hline \multirow[t]{2}{*}{$\begin{array}{l}\text { Picked } \\
\text { Drive unit }\end{array}$} & Type & $\begin{array}{c}\text { HD CD } \\
20 A \\
\text { (ratio } \\
100)\end{array}$ & $\begin{array}{c}\text { HD CD } \\
25 A \\
\text { (ratio } \\
100 \text { ) }\end{array}$ & $\begin{array}{c}\text { HD CD } \\
32 A \\
\text { (ratio 80) }\end{array}$ \\
\hline & $\begin{array}{l}\text { Mass } \\
{[\mathrm{kg}]}\end{array}$ & 3,9 & 6 & 8,4 \\
\hline \multirow[t]{2}{*}{$\begin{array}{l}\text { Alternative } \\
\text { Drive unit }\end{array}$} & Type & $\begin{array}{c}\text { Spinea } \\
\text { DS095 } \\
\text { (ratio 73) }\end{array}$ & $\begin{array}{c}\text { Spinea } \\
\text { DS110 } \\
\text { (ratio 67) }\end{array}$ & $\begin{array}{c}\text { Spinea } \\
\text { DS110 } \\
\text { (ratio 67) }\end{array}$ \\
\hline & $\begin{array}{l}\text { Mass } \\
{[\mathrm{kg}]}\end{array}$ & 5,9 & 9,7 & 9,7 \\
\hline
\end{tabular}

Table 4. Results of drive selection for Joint 4

\begin{tabular}{|c|c|c|c|c|}
\hline \multicolumn{5}{|c|}{ Joint 5} \\
\hline \multicolumn{2}{|c|}{ Values } & $\begin{array}{c}\text { Analysis } \\
1\end{array}$ & $\begin{array}{c}\text { Analysis } \\
2\end{array}$ & $\begin{array}{c}\text { Analysis } \\
3\end{array}$ \\
\hline \multirow{3}{*}{$\begin{array}{c}\text { Output } \\
\text { Torque } \\
\text { [ Nm ] }\end{array}$} & Max. & 30,32 & 65,12 & 123,91 \\
\hline & Avg. & 8,62 & 18,64 & 15,27 \\
\hline & Min. & 8,1 E-04 & 2,2 E-03 & 1,5 E-04 \\
\hline \multirow{3}{*}{$\begin{array}{l}\text { Output } \\
\text { Speed } \\
\text { [ rpm ] }\end{array}$} & Max. & 7,64 & 7,64 & 9,55 \\
\hline & Avg. & 3,29 & 3,29 & 5,96 \\
\hline & Min. & 0,00 & 0,00 & 0,00 \\
\hline \multirow{2}{*}{$\begin{array}{l}\text { Radial } \\
\text { force }\end{array}$} & Max. & 127 & 203,17 & 320,65 \\
\hline & Avg. & 36,88 & 60,18 & 69,1 \\
\hline [ N ] & Min. & 0,3 & 0,47 & 0,47 \\
\hline \multirow{3}{*}{$\begin{array}{c}\text { Axial force } \\
{[\mathrm{N}]}\end{array}$} & Max. & 283,126 & 363,39 & 436,65 \\
\hline & Avg. & 274,28 & 349,36 & 350,85 \\
\hline & Min. & 245,8 & 302,84 & 302,83 \\
\hline \multirow[t]{2}{*}{$\begin{array}{l}\text { Picked } \\
\text { Drive unit }\end{array}$} & Type & $\begin{array}{c}\text { Spinea } \\
\text { DS050 } \\
\text { (ratio 63) }\end{array}$ & $\begin{array}{c}\text { HD CD } \\
17 A \\
\text { (ratio } \\
100)\end{array}$ & $\begin{array}{c}\text { Spinea } \\
\text { DS } 095 \\
\text { (ratio 73) }\end{array}$ \\
\hline & $\begin{array}{l}\text { Mass } \\
{[\mathrm{kg}]}\end{array}$ & 1,4 & 2,3 & 5,9 \\
\hline \multirow[t]{2}{*}{$\begin{array}{l}\text { Alternative } \\
\text { Drive unit }\end{array}$} & Type & $\begin{array}{c}\text { HD CD } \\
14 \mathrm{~A} \\
\text { (ratio100) }\end{array}$ & $\begin{array}{c}\text { Spinea } \\
\text { DS070 } \\
\text { (ratio 57) }\end{array}$ & $\begin{array}{c}\text { HD CD } \\
25 A \\
\text { (ratio 50) }\end{array}$ \\
\hline & $\begin{array}{l}\text { Mass } \\
{[\mathrm{kg}]}\end{array}$ & 1,7 & 3,4 & 6 \\
\hline
\end{tabular}

The results show that both the change in the weight of the manipulated object and the change in the trajectory have a significant effect on the size of the drive units in the joints of the manipulator. This confirms the advantage of using DrivePicker software in the design of single-purpose devices. Even with a small change in boundary conditions, it is necessary to recalculate all selected drive units, which would take a large amount of time in the classic manual calculation. Furthermore, when comparing the basic parameters of selected drive units of both manufacturers in each joint for each analysis, such as size and weight, we can see significant differences in some cases. The CanisDrive series contains significantly more drive units of various sizes and performance parameters than the Spinea DS series.

For this reason, in some cases, a suitable Spinea DS series drive unit is much larger in size and weight than a suitable CanisDrive series drive unit, while similarly sized Spinea DS units weigh less than CanisDrive units. This fact also points to the effectiveness of DrivePicker software and its advantage in selecting and comparing drive units from several manufacturers. The use of DrivePicker software also significantly reduces the overall design time of the drive unit. Selecting a unit for one joint took 30 seconds using DrivePicker. A similar calculation performed manually took approximately an hour to an hour and a half.

\section{CONCLUSIONS}

In the previous chapters, the developed software tool for drive units design DrivePicker was described, from working with its GUI to the internal operation and the proposed algorithms for the choice of drive units. Verification of the proposed software solution's functionality and benefits was demonstrated on the task of designing drive units for a robotic arm model with five degrees of freedom. Harmonic Drive Canis Drive and SpineaDS drive units have been designed, which are currently the only ones the software works with. In addition to the demonstration of functionality, both manufacturers' resulting designed units were also compared in terms of their weight parameters. As part of further development, not only the expansion of algorithms and database for drive units of other series and manufacturers is planned, but also the possibility of direct connection with applications for designing standardized and non-standardized elements used in mechatronic device construction, generating and assembling their models, and software for performing dynamic and static strength or motion analyzes via their API interface. The vision is a software package with which it would be possible to automate the design of mechatronic devices from conceptual design to the final 3D model.

Table 5. Results of drive selection for Joint 5 


\section{ACKNOWLEDGMENTS}

This article has been elaborated under support of the project Research Centre of Advanced Mechatronic Systems, reg. no. CZ.02.1.01/0.0/0.0/16_019/0000867 in the frame of the Operational Program Research, Development and Education. This article has been also supported by specific research project SP2020/141 and financed by the state budget of the Czech Republic.

\section{REFERENCES}

[MITCalc 2021] MITCalc - Mechanical, Industrial and Technical Calculations. [online]. Available from https://www.mitcalc.com/

[KISSsoft 2021] KISSsoft AG. [online]. Copyright (C2021 KISSsoft AG [cit. 16.02.2021]. Available from: https://www.kisssoft.com/en

[Reddy 2015] Esanakula, Jayakiran \& Sridhar, ·Naga venkata \& Rangadu, Vootukuri. (2015). Knowledge - Based Parametric Modeling for Bolts, Nuts and Bearings using SolidWorks. International Journal of Applied Engineering Research. 10. 16111-16120.

[Reddy 2018] E. Jayakiran Reddy, N. Venkatachalapathi, V. Pandu Rangadu. (2018). Development of an approach for Knowledge-Based System for CAD modelling. Materials Today: Proceedings. ISSN 22147853

[Harmonic Drive 2021] Harmonic Drive SE. 301 [online]. Copyright (C) 2021 [cit. 25.02.2021]. Available from: https://harmonicdrive.de/en/home

[Spinea 2021] SPINEA - Excellence in motion [online]. Available from: https://www.spinea.com/

\section{CONTACTS:}

Ing. Zdenek Zeman

VSB - Technical University of Ostrava, Department of Robotics 17. listopadu 2172/15, Ostrava, 708 00, Czech Republic

+420 597321 209, zdenek.zeman@vsb.cz, www.fs.vsb.cz/354 